\title{
BMJ Open Alcohol consumption of UK members of parliament: cross-sectional survey
}

To cite: Rao R, Bakolis I, Das-Munshi J, et al. Alcohol consumption of UK members of parliament: crosssectional survey. BMJ Open 2020;10:e034929. doi:10.1136/ bmjopen-2019-034929

- Prepublication history for this paper is available online. To view these files, please visit the journal online (http://dx.doi. org/10.1136/bmjopen-2019034929).

Received 11 October 2019 Revised 30 November 2019 Accepted 15 January 2020

Check for updates

(C) Author(s) (or their employer(s)) 2020. Re-use permitted under CC BY-NC. No commercial re-use. See rights and permissions. Published by BMJ.

${ }^{1}$ Old Age Psychiatry, Institute of Psychiatry, Psychology and Neuroscience, London, UK

${ }^{2}$ King's College London, London, UK

${ }^{3}$ Section of Epidemiology, Department of Health Service \& Population Research, King's College London, Institute of Psychiatry, London, UK

${ }^{4}$ South London and Maudsley NHS Foundation Trust, London, UK

${ }^{5}$ Institute of Psychiatry,

Psychology and Neuroscience, King's College London, London, UK

${ }^{6}$ Health Service and Population Research, Institute of Psychiatry, London, UK

Correspondence to

Dr Rahul Rao;

tony.rao@kcl.ac.uk

\author{
Rahul Rao (1) , ${ }^{1}$ Ioannis Bakolis, ${ }^{2}$ Jayati Das-Munshi, ${ }^{3}$ Daniel Poulter, ${ }^{4}$ \\ Nicole Votruba (D) , ${ }^{5}$ Graham Thornicroft ${ }^{6}$
}

\begin{abstract}
Objectives This study examined the prevalence of risky drinking by members of parliament (MPs), as well as the relationship between risky drinking and age, years spent as an MP, working outside parliament, awareness of the Parliamentary Health and Wellbeing Service, and probable mental ill health.
\end{abstract}

Design A survey questionnaire assessed alcohol consumption using the Alcohol Use Disorders Identification Test (AUDIT). Risky drinking was identified by combining categories of increasing (hazardous), higher (harmful) and probable dependent drinking for those with a total score of 8 or more. Comparator groups from the 2014 Adult Psychiatric Morbidity Survey (APMS) were used as controls.

Setting UK House of Commons.

Participants $650 \mathrm{MPs}$.

Results Compared with all 650 MPs, participants $(n=146)$ were more likely to be female $(p<0.05)$ or have an educational qualification $(p<0.05)$. Weighted proportions on AUDIT items were higher than the APMS comparator group for participants who had a drink four or more times a week, 10 or more drinks on a typical drinking day, six or more drinks in one occasion, or felt guilty because of drinking $(p<0.01)$. Weighted percentages for risky drinking were higher in MPs compared with the whole English population $(p<0.05)$, but similar when compared with socioeconomic comparator groups. The odds of risky drinking were 2.74 times greater for MPs who had an additional work role outside parliament compared with those who did not $(95 \% \mathrm{Cl} 0.98$ to 7.65$)$ and 2.4 times greater for MPs with probable mental ill health compared with those with no evidence of probable mental ill health (95\% Cl 0.78 to 7.43 ).

Conclusions A low level of awareness of the Parliamentary Health and Wellbeing Service has implications for improving the detection of risky drinking and improving access to this service by MPs. Possible increased likelihood of risky drinking in MPs who also had an additional work role outside Parliament and among those with probable mental ill health requires further exploration.

\section{INTRODUCTION}

The health and social costs of alcohol to the UK are very considerable, amounting to $£ 21$ billion per year. ${ }^{1}$ Between 2006 and 2015, alcohol specific deaths rose by $9 \%$ for men and $14 \%$ for women. ${ }^{2}$ Between 2016 and 2017, the
Strengths and limitations of this study

The study used recognised screening tools to assess alcohol use and mental health.

- The findings warrant further exploration of the determinants and consequences of and access to support for mental ill health and risky drinking in UK members of parliament (MPs).

- The low response rate and possibility of underreporting represent potential selection biases.

- The study may be underpowered to test for specific hypotheses.

- The increased likelihood of risky drinking both in MPs with additional employment outside parliament and those MPs with probable mental ill health is weakened by the small sample size.

number of hospital admissions in England wholly or partly attributable to alcohol was 337867 , a rise of $15 \%$ from 2007 to $2008 .^{3}$ One in five patients admitted to hospital in the UK have harmful use of alcohol, and one in 10 are alcohol-dependent. ${ }^{4}$

Despite increases in alcohol-related deaths and hospital admissions, paradoxically there has been a fall in the proportion of people in England who report drinking alcohol at least once a week.

In 2006, this applied to $72 \%$ of men and $58 \%$ of women, reducing to $58 \%$ and $42 \%$ for men and women, respectively, in $2017 .{ }^{5}$ However, $28 \%$ of men and $14 \%$ of women in England still drink at levels indicating an increased or high risk of alcohol-related harm. ${ }^{5}$

Alcohol use among civil servants has been studied extensively in the Whitehall studies that explored social determinants of health, with clear findings of adverse effects on cardiovascular ${ }^{6}$ and cognitive ${ }^{7}$ function associated with drinking at levels above recommended guidelines. Although high workloads, job stress and using alcohol to unwind after work are known to be associated with risky drinking, ${ }^{8}$ this has so far not been studied in UK parliamentarians. 
All members of parliament (MPs) have access to the Parliamentary Health and Wellbeing Service, an occupational health service which provides a confidential, professional, independent, advisory service that also covers alcohol related health problems through medical screening services. ${ }^{9}$ Given the confidential nature of this service, information on health is not shared with an MP's own general practitioner. This study is part of a complementary analysis of a wider study that found higher rates of mental health problems in MPs compared with the English population as a whole. ${ }^{10}$

The principal research question of this study was: (1) What is the prevalence of risky (hazardous, harmful, dependent) drinking among MPs? The secondary questions were: (2) Do MPs who work outside parliament have an increased probability of risky drinking than those who do not? (3) Do older MPs ( $>50$ years old) have an increased probability of risky drinking compared with their younger counterparts? (3) Are more years served as an MP (>16 years) associated with greater risky drinking? (4) Do MPs with probable mental ill health have a higher probability of risky drinking? (5) Are MPs with risky drinking less aware of the Parliamentary Health and Wellbeing service?

This study tested the following primary hypotheses: (1) the occurrence of risky drinking by MPs is higher than the general population; and (2) it is higher than comparator specific sociodemographic, professional and occupational groups.

\section{METHODS}

\section{Study design and participants}

We conducted an anonymised, online self-completed survey at the House of Commons in December 2016. The inclusion criteria for participation were: membership of the 56th UK Parliament, House of Commons and providing written, informed consent. We followed the STROBE (STrengthening the Reporting of OBservational studies in Epidemiology) guidelines for observational studies for the reporting of this cross-sectional study. ${ }^{11}$ No age limits were defined, except that to be elected to parliament one must be over 18 years old. Initially, in November 2016 a letter was sent to all 650 members of the House of Commons to make them aware of the study. In early December, a letter including a web link to an online survey with an individual access code was sent out to all MPs via internal post, and via email. The survey took place between 5 and 31 December 2016. Repeated efforts were taken to promote participation and maximise response rates in the survey. The study information sheet (explaining the purpose of the study) and instructions for the online questionnaire, as well as two reminder emails, were sent out with clear descriptions of encrypted data collection and protection measures to ensure anonymity.

\section{Ethics and data protection}

At all times throughout the study preparation, conduct and analysis, particular consideration and care was given to the nature of study context, and to the potential vulnerability of participants, namely the risk of sensationalised coverage should any individual be identifiable. Ethics approval for the study was obtained in September 2016 from King's College London Ethics Committee (reference number: HR-16/17-3118). Efforts were taken to limit distress and secure confidentiality for the participants. To ensure full confidentiality, no personal identifiers were requested, and any identifiers were removed if provided. All participants were provided with contact information for the Parliamentary Health and Wellbeing Service in the introductory letter and via the online survey in case any participants were experiencing distress at the time of the survey.

\section{Adult Psychiatric Morbidity Survey comparator groups}

Data for the comparator groups were elicited from the Adult Psychiatric Morbidity Survey (APMS) (2014). The APMS is a survey which provides data on the prevalence of both treated and untreated psychiatric disorders in the English adult population (aged 16 and over). APMS uses a robust, stratified, multi-stage probability sample of households to sample nationally a representative random cross section of the population of England every 7 years. Participants are visited by an interviewer who collects demographic and socioeconomic data and assesses psychiatric disorders via actual diagnostic criteria. A detailed description of the APMS has been reported elsewhere. ${ }^{12}$

From the APMS, we identified four comparison groups: (1) total population of England in the APMS England population (EN); (2) corporate managers in England (CM); (3) all managers in England (AM); and (4) those in high-income groups in England (HIG). The socioeconomic groups derive from a standardised questionnaire asked in the APMS to all survey respondents.

\section{Measures of alcohol consumption}

The primary measure presented in this paper is the Alcohol Use Disorders Identification Test (AUDIT). ${ }^{13}$ The AUDIT takes the year before the interview as a reference period, consists of 10 items and covers the following areas: (1) alcohol consumption (frequency of drinking, typical quantity, frequency of heavy drinking); (2) alcoholrelated harm (feeling of guilt or remorse after drinking, blackouts, alcohol-related injury, other concern about alcohol consumption); and (3) symptoms of alcohol dependence (impaired control over drinking, increased salience of drinking, morning drinking). Answers to all questions are scored from 0 to 4 and summed to give a total score ranging from 0 to 40 . A score of $\leq 7$ classifies non-drinkers or low risk drinking, while a score of $\geq 8$ classifies hazardous, harmful or dependent drinking. Risky drinking was defined as all those in the harmful, hazardous or dependence categories. ${ }^{14}$ 


\section{Covariates}

Core demographic questions were obtained from the UK Parliamentary Mental Health (UKPMH) study sample: age (categorised into five groups: 21 to $30 ; 31$ to $40 ; 41$ to $50 ; 51$ to $60 ; 61$ to $70,>70$ years); sex (female or male); educational status (GCSE/O level, A level, vocational qualifications, undergraduate degree, postgraduate degree, doctorate); and years serving as an MP. Exploring other variables was limited by the possibility of being identified, while maintaining core sociodemographic information and other relevant influences on alcohol consumption.

The General Health Questionnaire (GHQ-12) was used to assess the mental health of respondents in the UKPMH sample as described in detail. ${ }^{15}$ Scoring of the GHQ-12 for the present study was done using the original bimodal method as developed by Goldberg. ${ }^{16} 17$ Specifically, each symptom was scored either 0 if "not at all present" or present "no more than usual", or 1 for symptoms that were present "rather more than usual" or "much more than usual".

The scoring method allowed for total scores to range from 0 to 12 . No formal threshold exists for identifying probable mental ill health, with optimal values likely to be specific to the population under study. All questions refer to symptoms experienced over the past 2 weeks.

However, in line with the previous Health Survey for England, ${ }^{18}$ MP's total scores are grouped according to three categories: 0 (indicating no evidence of probable mental ill health), 1 to 3 (indicating less than optimal mental health), and $\geq 4$ (indicating probable psychological disturbance or mental ill health).

MPs were also asked if they were aware of the mental health and wellbeing support provided by the Parliamentary Health and Wellbeing service. Ethnicity was not assessed. We also assessed if the MP had a job outside the parliament and the years serving as an MP. Owing to the low number of MPs from a minority ethnic background in the 56th House of Commons $(n=41)$, this avoided any concern about the identification of participants, which may have further limited the response rate.

\section{Statistical analyses}

All statistical analyses were performed using STATA 14.1. ${ }^{19}$ Within the UKPMH sample, descriptive analyses were undertaken first to determine the distribution of each item of the AUDIT and of sociodemographic characteristics and awareness of mental health services.

The UKPMH sample is subject to "unit non-response" as $22.4 \%$ of all MPs completed the survey. To address this issue, we employed inverse probability weighting ${ }^{20}$ in the analysis, where weights were used to rebalance the set of complete cases within the MP sample to make it representative of the whole English population; we used the survey weighted sample of the APMS 2014. Age-sex standardised proportion estimates were calculated: (1) for each item of the AUDIT, and (2) for the presence of risky drinking.

We compared (1) each item of the AUDIT, and (2) the total score of the AUDIT derived from the combined categories that indicate the presence of risky drinking of the MP sample, with a range of sociodemographic groups (the English population (EN), corporate managers (CM), all managers (AM), and with high income groups (HIG) in England) derived from APMS 2014.

Non-parametric tests $\left(\chi^{2}\right)$ and parametric tests (t-test for unequal sample sizes) were employed to explore potential differences in the proportion estimates between UKPMH and APMS 2014 samples.

Differences between the sample group and the MP group as a whole for time were examined for time served as an MP, age and sex of an MP, presence of higher education, having a job outside parliament, awareness of the Parliamentary Health and Wellbeing Service, presence of probable mental ill health and risky (hazardous, harmful and dependent) drinking. Risky drinking was also explored as a dependent variable in exploring its association with the other variables listed, using logistic regression models.

Results were expressed as increased risk (odds ratio and corresponding 95\% confidence intervals) of risky drinking for those MPs aged $>50$ years old compared with $<50$ years old; years of service $>16$ compared with $<16$; awareness compared with lack of awareness of the Parliamentary Health and Wellbeing Service; having a job compared with not having a job outside the parliament; and having probable mental ill health compared with not having probable mental ill health. All models were adjusted for the following potential confounders identified a priori: age, sex and educational status. Age-sex standardised inverse probability weights were employed for logistic regression models.

\section{Patient and public involvement}

Dr Daniel Poulter, MP, was involved at all stages of the study and is co-author of the paper. Other parliamentarians and staff of the Parliamentary Health and Wellbeing Service were consulted at the planning and design stages, as well as at the interpretations of the findings and dissemination stages of the study.

\section{RESULTS}

Questionnaires were returned by 146 respondents $(22.4 \%)$ of the 650 MPs. Median time to complete the survey was $4 \mathrm{~min}$ (IQR 3-5 min). Most respondents were male $(63 \%)$ and $24 \%$ had a postgraduate degree. Just over half were above 50 years old $(51 \%)$, and most did not work outside parliament $(81 \%)$, served $<16$ years $(81 \%)$, and were unaware of the Parliamentary Health and Wellbeing Service $(77 \%)$ (see table 1 ).

\section{Characteristics of respondents in comparison to all MPs}

Compared with all $650 \mathrm{MPs}$, those who participated were younger $(18 \%(n=27)$ vs $16 \%$ of total MP population were below 40 years old; $p$ of $\chi^{2}$ test $>0.05$ ), were more likely to be female $(37 \%(n=54)$ of the UKPMH sample vs $30 \%$ of total MP population were female; $p$ of $\chi^{2}$ test $<0.05$ ) 
Table 1 Demographic characteristics of UKPMH participants

\begin{tabular}{|c|c|c|}
\hline & $\begin{array}{l}\text { MP } \\
\text { sample } \\
(n=146) \\
\end{array}$ & $\begin{array}{l}\text { Total adult } \\
\text { psychiatric } \\
\text { morbidity } \\
\text { sample } \\
(\mathrm{n}=7546)\end{array}$ \\
\hline & $\mathbf{N}(\%)$ & $\mathbf{N}(\%)$ \\
\hline Below 50 years old & $71(49)$ & $4124(51)$ \\
\hline Female & $54(37)$ & $4385(55)$ \\
\hline Postgraduate degree & $35(24)$ & $553(3)$ \\
\hline $\begin{array}{l}\text { Unaware of Parliamentary Health and } \\
\text { Wellbeing Service }\end{array}$ & $112(77)$ & $\mathrm{n} / \mathrm{a}$ \\
\hline Years serving as MP (>16 years) & $118(81)$ & $\mathrm{n} / \mathrm{a}$ \\
\hline Work outside parliament & $27(19)$ & $\mathrm{n} / \mathrm{a}$ \\
\hline $\begin{array}{l}\text { Risky (hazardous, harmful, dependent) } \\
\text { drinking }\end{array}$ & $42(29)$ & $1197(20)$ \\
\hline
\end{tabular}

Presence of probable mental ill health

$\begin{array}{lll}\text { No evidence of probable mental ill health } & 35(25) & 4256(54) \\ \text { Less than optimal mental ill health } & 62(40) & 1620(20) \\ \text { Probable mental ill health } & 49(35) & 2141(26)\end{array}$

PM, member of parliament; UKPMH, UK Parliamentary Mental Health.

and were more likely to have an educational qualification ( $81 \%$ of the UKPMH sample vs $76 \%$ of total MP population; $\mathrm{p}<0.05)$.

\section{Alcohol consumption of MPs and the APMS 2014 comparator groups}

Table 2 presents weighted percentage estimates and corresponding 95\% CIs of the UKPMH sample and the four different predetermined APMS 2014 occupational and sociodemographic comparator groups (EN, CM, AM, HIG). For each item of the AUDIT, the UKPMH sample presented a higher weighted percentage of participants who had a drink four or more times a week, had 10 or more drinks on a typical drinking day, had six or more drinks on one occasion, or felt guilty because of drinking ( $p$ values of $\chi^{2}$ test $<0.01$ ) compared with the four APMS 2014 occupational and sociodemographic comparison groups (table 2).

However, a similar weighted percentage of MPs were not able to stop drinking after they started, failed to do what was normally expected because of drinking, and had no memory of the night before because of their drinking ( $p$ values of $\chi^{2}$ test $>0.05$ ) compared with APMS 2014 occupational and sociodemographic comparison groups (table 2). Finally, compared with the four APMS 2014 occupational and sociodemographic comparison groups, a lower weighted percentage of MPs were injured because of drinking $(\mathrm{p}<0.001)$ (table 2$)$.

When we compared the weighted percentages of the combined categories derived for the AUDIT total score that indicate the presence of risky drinking between the UKPMH and APMS 2014 samples, we found a higher proportion of MPs with risky drinking (weighted percentage $29 \%, 95 \%$ CI $22 \%$ to $37 \%$ ), compared with the English population (weighted percentage 20\%, $95 \%$ CI $19 \%$ to $21 \%$; p value of $\chi^{2}$ test $<0.05$ ) and similar weighted proportions when compared with corporate managers (weighted proportion 25\%, 95\% CI 21\% to $29 \%$ ), all managers (weighted percentage $24 \%, 95 \%$ CI $20 \%$ to $27 \%$ ) and high-income groups (weighted proportion $27 \%, 95 \%$ CI $25 \%$ to $30 \%$ ) ( $p$ values of $\chi^{2}$ test $>0.05$ ) (see table 2 and figure 1 ).

\section{Time served as an MP, job status, age and awareness of the} Parliamentary Health and Wellbeing Service

After adjusting for age, sex and educational status, we found no association between risky drinking (combined categories of increasing, higher risk and probable dependence) and being older than 50 years old, serving more than 16 years in parliament, and not being aware of the Parliamentary Health and Wellbeing Service (table 3). For MPs who worked both inside and outside parliament, the odds of risky drinking were 2.74 times greater in MPs who also worked outside compared with those who worked only within parliament. However, precision of estimates were impacted on by the smaller sample size.

Similarly, the odds of risky drinking were 2.4 times greater for MPs with probable mental ill health than those with no probable mental ill health. The precision of the estimates were influenced by the relatively small sample size.

\section{DISCUSSION}

\section{Principal findings}

The main research objective in this study was to explore risky (hazardous, harmful and dependent) drinking among MPs. The study tested the primary hypothesis that the occurrence of risky drinking by MPs is higher compared with the general population and specific sociodemographic, professional and occupational groups. The overall rate of risky drinking was higher than in the English population but did not differ significantly from groups comparable in both socioeconomic and occupational status. However, there were higher weighted averages among MPs for drinking at least four times per week, drinking at least 10 units on a typical drinking day, drinking 6 units or more in a single drinking episode, and feeling guilty about their drinking.

There were also five secondary questions to be addressed. These were whether risky drinking is more likely: in MPs with a job outside parliament; in MPs aged over 50; in MPs with >16 more years of service; in MPs who were unaware of the Parliamentary Health and Wellbeing Service; and in MPs with probable mental ill health. In multivariable logistic regression models, we did not find an association between risky drinking and age, years served in parliament or awareness of the Parliamentary Health and Wellbeing Service. There was a trend towards risky drinking being more likely in MPs who reported also working outside parliament. However, the strength of 


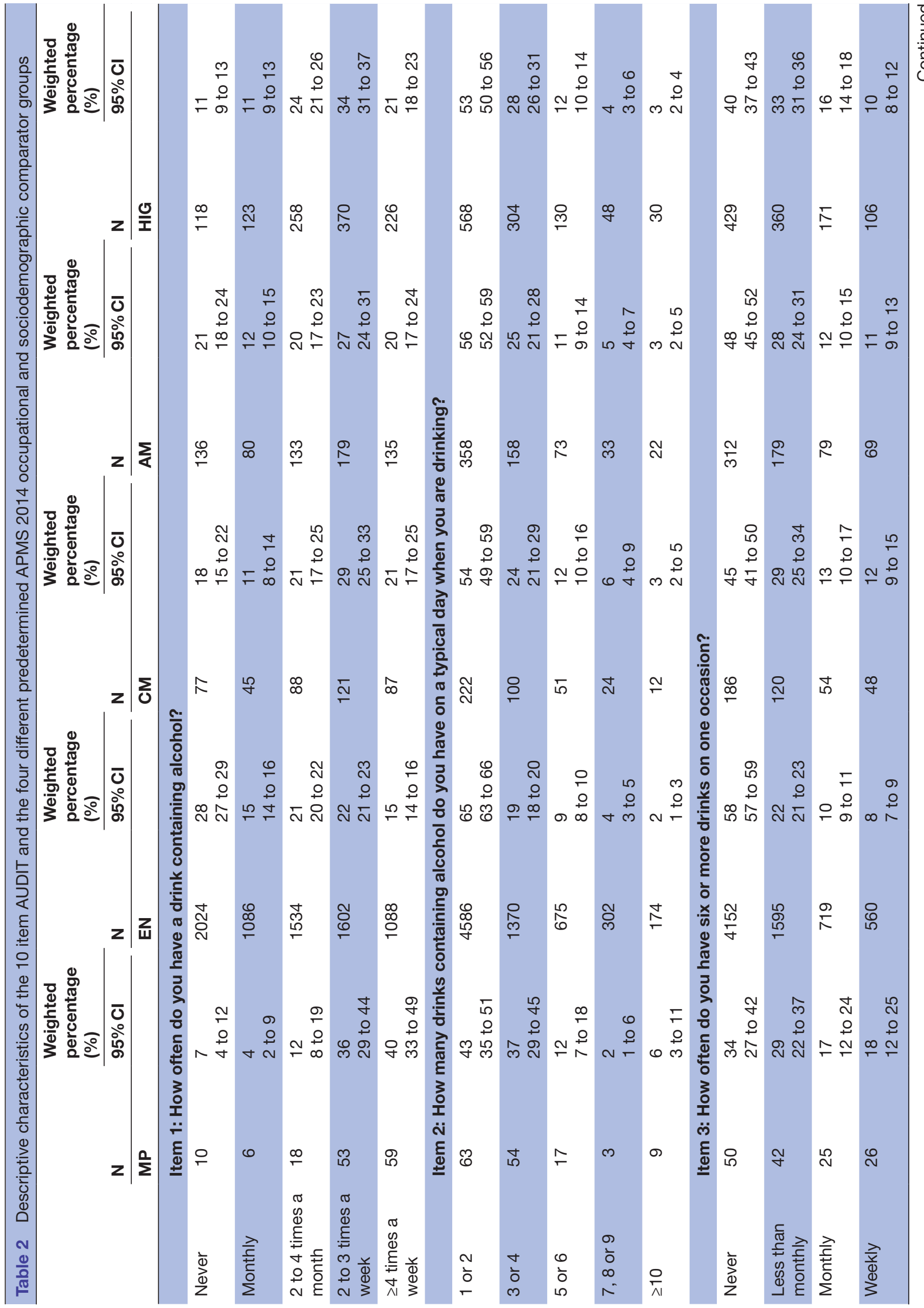




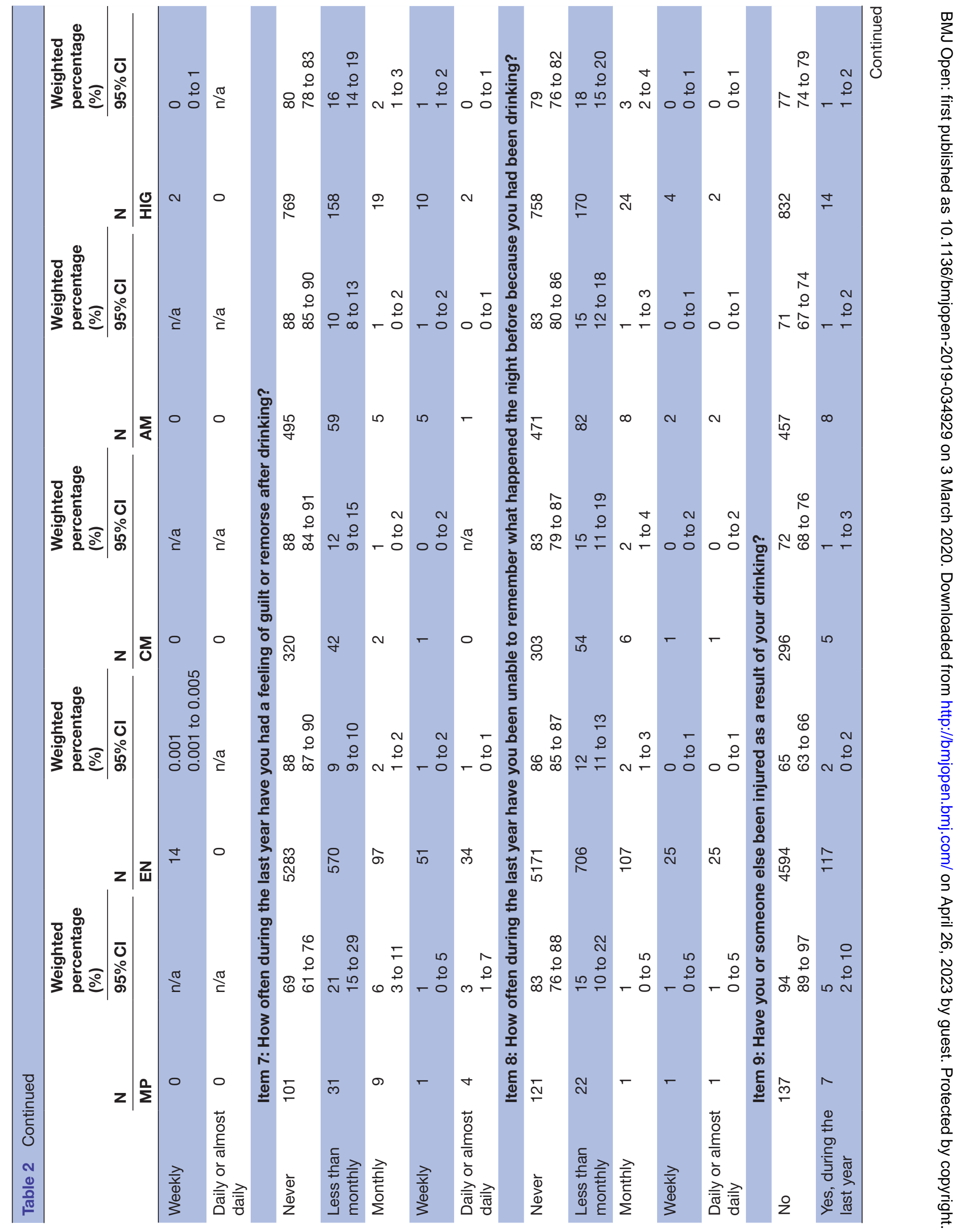




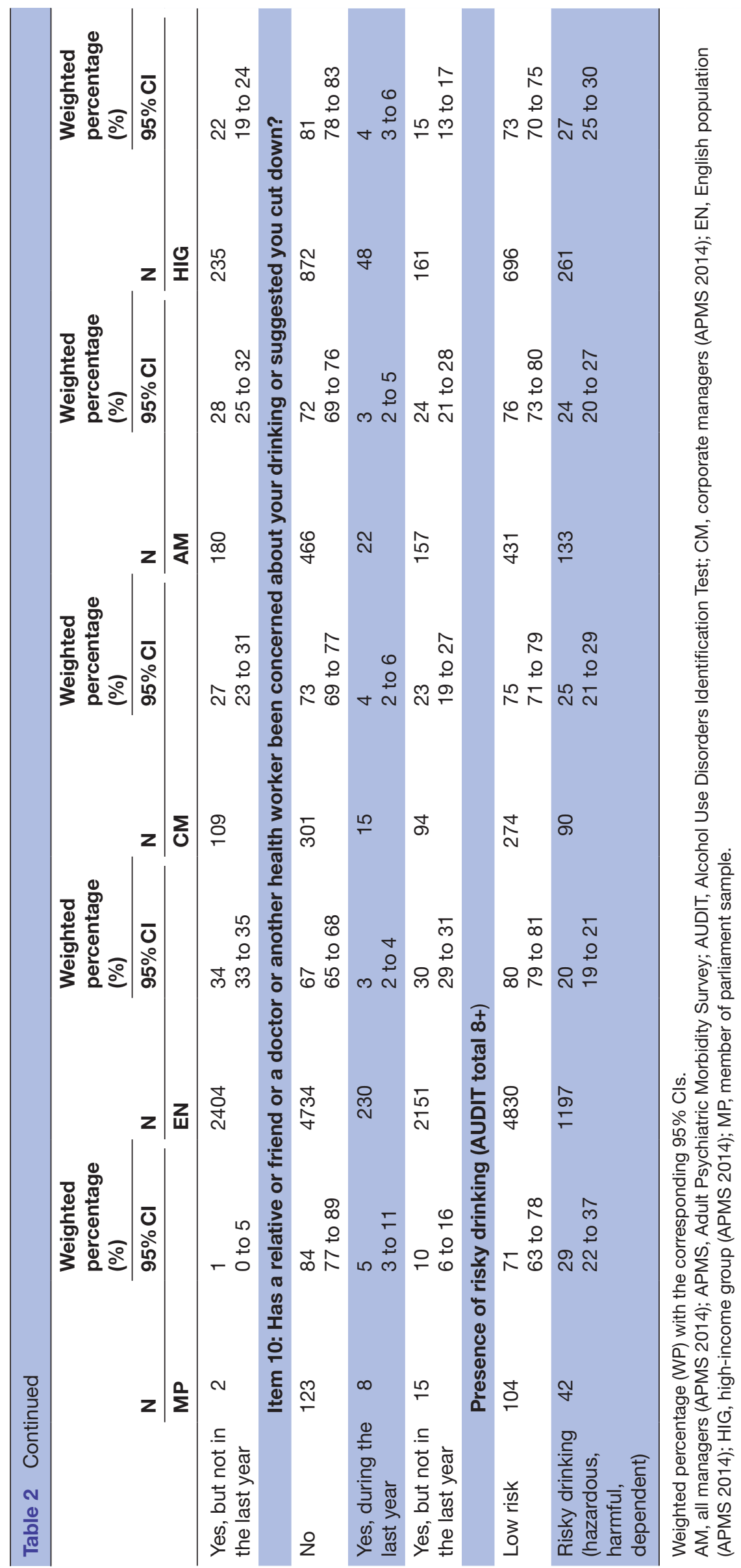




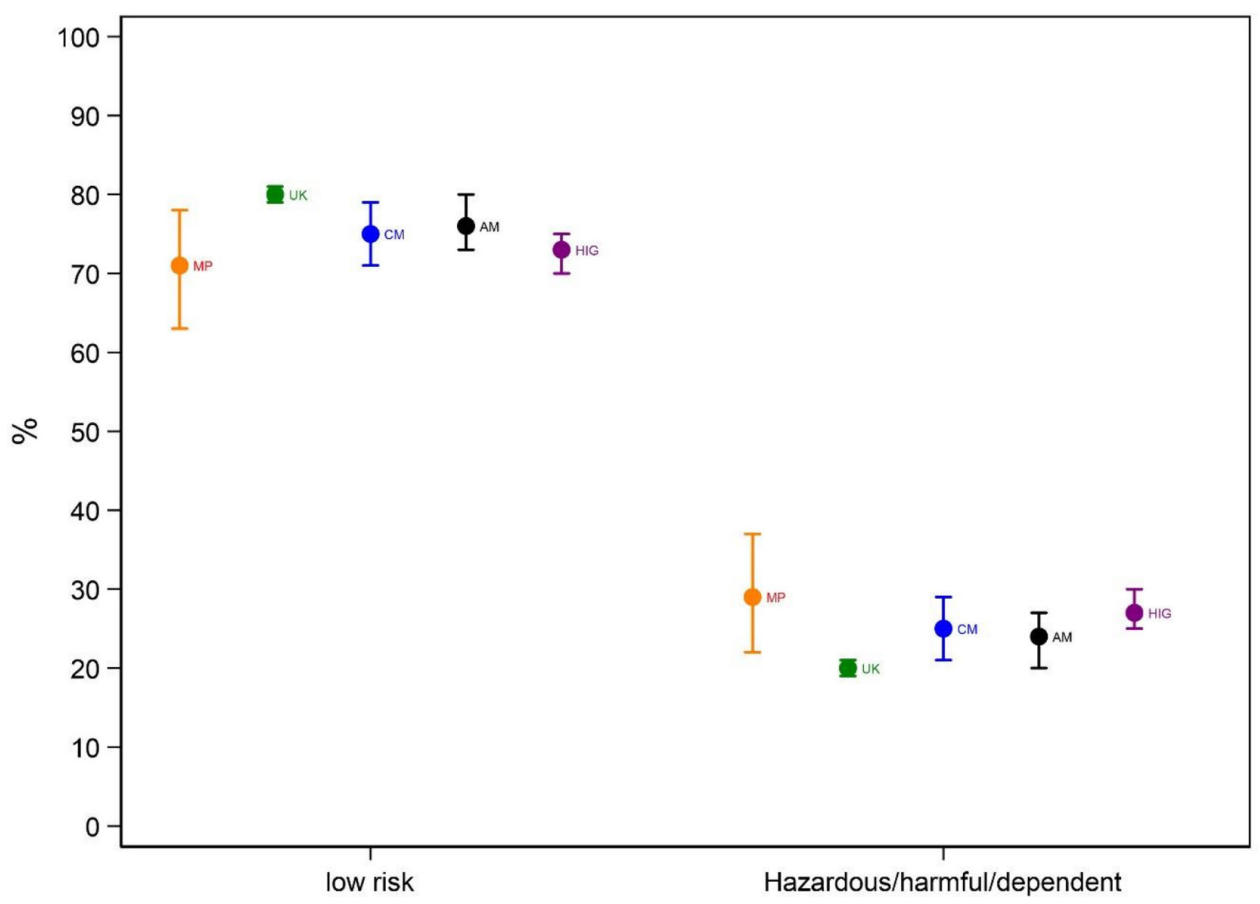

Figure 1 Age-sex standardised prevalence estimates and 95\% Cls of UKPMH and of specific population groups of APMS 2014 for the two different categories of AUDIT. AM, all managers (APMS 2014); APMS, Adult Psychiatric Morbidity Survey; AUDIT, Alcohol Use Disorders Identification Test; CM, corporate managers (APMS 2014); EN, English population (APMS 2014); HIG, high-income group (APMS 2014); MP, member of parliament sample; UKMPH, UK Parliamentary Mental Health.

evidence for such an association was weak and may have been impacted on by a smaller sample size. Similar results were observed with the presence of probable mental ill health.

\section{Strengths and weaknesses of the study}

The study has several limitations. First, the response rate was relatively low $(22.4 \%)$, representing a potential selection bias. Given the intense workload of MPs, this may have been partly due to the additional workload of completing the survey, even though the median time to complete the survey was only $4 \mathrm{~min}$. Notably, a possible fear of being identified, of stigmatisation, and of the potential reputational damage associated with adverse media coverage may have influenced the response rate. We tried to reduce these biases by promoting the survey in parliament, by sending several reminders, and by stressing the brevity as well as the anonymity of the survey. In spite of this, the response rate was low. Generally, MPs

Table 3 Univariate and multivariate logistic regression analysis for risky drinking (combined categories of AUDIT low risk, risky (hazardous, harmful, dependent)) in relation to job status (having a job outside the parliament vs not), being older than 50 years old (vs not), years serving as an MP (above 16 years vs not), awareness of Parliamentary Health and Wellbeing Service (vs not) and presence of probable mental ill health (vs not) in MPs

\begin{tabular}{|c|c|c|c|c|}
\hline \multirow[b]{2}{*}{$n=146$} & \multicolumn{2}{|c|}{ Crude $^{*}$} & \multicolumn{2}{|c|}{ Adjusted* } \\
\hline & OR & $95 \% \mathrm{Cl}$ & OR & $(95 \% \mathrm{Cl})$ \\
\hline Work outside parliament & 2.37 & 0.99 to 5.63 & 2.74 & 0.98 to 7.65 \\
\hline Served as MP >16years & 1.22 & 0.50 to 2.96 & 0.86 & 0.33 to 2.24 \\
\hline Unaware of Parliamentary Health and Wellbeing Service & 0.60 & 0.28 to 1.25 & 0.55 & 0.23 to 1.67 \\
\hline No evidence of probable mental ill health & 1 & & 1 & \\
\hline Less than optimal mental ill health & 1.15 & 0.42 to 3.11 & 1.54 & 0.52 to 4.61 \\
\hline Probable mental ill health & 1.93 & 0.71 to 5.24 & 2.40 & 0.78 to 7.43 \\
\hline
\end{tabular}

${ }^{*}$ Crude and adjusted ORs with corresponding 95\% Cls. Inverse probability weights were used with reference to the total number of the members of the parliament. All models were adjusted for age, sex and educational status.

MP, member of parliament. 
are a difficult survey population to engage, which has also been confirmed in a 2008 internal UK parliament survey, where only $14.5 \%$ (94 MPs) responded. ${ }^{20}$

Second, it is also possible that MPs who did not respond to the online survey may have had an increased risk of risky drinking and were therefore under-represented in the study sample. There is also a potential risk of underreporting from people who took part in the study, because of the stigma associated with the topic.

Compared with the UKPMH population, respondents were younger in age distribution (18\% of the UKPMH sample vs $16 \%$ of the total MP population were below 40 years old; $\mathrm{p}>0.05$ ), with a higher proportion of females (36\% female of the UKPMH sample vs $30 \%$ of total MP population were female; $\mathrm{p}<0.05)$ and those with an educational qualification $(81 \%$ of the UKPMH sample vs $76 \%$ of total MP population; $\mathrm{p}<0.05)$. We did not assess marital or cohabitation status, as this would have increased the risk of identifiability of MPs, and this may have therefore also adversely affected the response rate. This was also the case for not including information on variables such as family history of mental disorder or religious belief.

In this sample we found that being an older MP $(>50$ years), serving $>16$ years as an MP, and being unaware of the Parliamentary Health and Wellbeing Service do not appear to constitute an increased risk for hazardous, harmful or dependent drinking. However, we regard this outcome with caution as this study may be underpowered to test for these specific hypotheses. Although we found a trend of an increased likelihood of risky drinking in MPs with additional employment outside parliament and in MPs with probable mental ill health, the strength of this likelihood was weakened by the small sample size.

\section{Comparison of results with earlier studies}

Although there have been previous surveys of mental health in UK MPs, ${ }^{102}$ this is the first study to examine the presence of risky drinking in this group. There have been four previously published studies exploring drinking in MPs, all from Europe. Response rates were higher than in the present study, ranging from $43-84 \%$.

In a study of $150 \mathrm{MPs}$ in the Dutch parliament, ${ }^{22}$ $7 \%$ reported drinking six drinks or more (7.5 UK units) at least once a week. Although the quantity of pure alcohol per drink was slightly more than in the present study, their finding was considerably less than the $18 \%$ in this study and was comparable to their control group matched for age and educational status. Another study involving 150 members of the Belgian parliament found that $59 \%$ drank more than one drink (1.3 UK units) per day, ${ }^{23}$ which was more than the $40 \%$ of MPs in the current study who drank 1-2 units or more at least four times per week. As in the present study, the proportion drinking more than one drink (1.3 UK units) per day was higher than in a control group of parliamentary employees.

Two other studies examined the mean number of drinks consumed per week. In a study of 200 MPs in the Finnish parliament ${ }^{24}$ compared against an age and sex matched control group as part of a population study of cardiovascular disease, there was no difference in the mean weekly amount for men, but women had a higher mean weekly consumption. A study of 102 MPs in the Danish parliament ${ }^{25}$ using a control group as part of a population study of cardiovascular disease found that the mean number of weekly drinks was more among MPs for wine but not for beer.

\section{Interpretation of results}

The current study is limited by somewhat small numbers, which limits the interpretation of the findings of MPs being more likely to display risky drinking if they have additional employment commitments outside parliament or have probable mental ill health.

The overall rate of risky drinking did not significantly differ from groups comparable in both socioeconomic and occupational status. However, the findings of higher weighted averages for drinking at least four times per week, drinking at least 10 units on a typical drinking day, drinking 6 units or more in a single drinking episode and feeling guilty about their drinking raises concerns both about overall weekly consumption and over possible binge drinking.

These drinking patterns were not associated with alcohol-related harm or symptoms indicative of dependence, yet there remains the possibility of escalation into more serious alcohol-related harm. The selection bias of the sample of responders containing a higher proportion of women compared with the whole MP group, as well as the possibility of under-reporting through concerns over stigma, may underestimate both the quantity and frequency of risky drinking and the presence of alcoholrelated harm. It may have also underestimated the likelihood of even greater differences in risky drinking for MPs with additional employment outside parliament and those with probable mental ill health.

\section{Implications for future research}

There is considerable scope for further exploration of the relationship between both overall risky drinking and alcohol-related harm in a larger, more representative sample of MPs. In particular, the impact of occupational stressors and mental ill health are worthy of attention. We are not aware of arrangements for mental health support for members of parliament outside the UK. Further examination of alcohol availability is warranted, as we understand that there are 30 bars, restaurants and hospitality suites at which alcohol is available or sold in the Palace of Westminster, and six bars open most evenings when MPs are voting or waiting to vote. The relative consumption of alcohol within and outside parliament is also worthy of further study, although it would be reasonable to assume that the majority of alcohol is consumed on the parliamentary estate, given the late working hours. Although beer and wine are provided free to members of the Belgian parliament, ${ }^{26}$ we are not aware of the availability 
of alcohol within other parliaments-but this is not generally a feature of the modern workplace.

Politicians are subject to increased scrutiny that may involve intrusive and aggressive behaviours from the public in the form of attack/attempted attack, threats to harm and property damage. It is known that over half of MPs may experience stalking or harassment. ${ }^{27}$

This has implications for both mental ill health and the potential risky use of alcohol. Stalking is known to be associated with a higher likelihood of mental disorders such as depression, panic disorder, generalised anxiety disorder and somatoform disorder. ${ }^{28}$

Work-related stress is known to be associated with long working hours and time pressures, lack of emotional support, family and constituency problems and job insecurity. ${ }^{29}{ }^{30}$ It is also associated with risky drinking, especially in work environments where alcohol is readily accessible. $^{31}$

\section{CONCLUSION AND POLICY IMPLICATIONS}

Over three quarters of the participants in this study were unaware of the Parliamentary Health and Wellbeing Service. Given the considerable stigma associated with mental health problems, ${ }^{32}{ }^{33}$ there is a need for MPs to be better informed about their own wellbeing service, to reduce stigma and improve help seeking within Parliament. ${ }^{34}$ The under-represented group of older men in this study is also of relevance, given rising rates of alcohol misuse in older people, ${ }^{35}$ particularly in those with higher socioeconomic status. ${ }^{36}$

Twitter Rahul Rao @kentjrchess, Jayati Das-Munshi @Jaydasmunshi and Nicole Votruba @NicoleVotruba

Acknowledgements We would like to thank all members of parliament who took part in this study. In addition, we would like to thank Elaine Bryce (member of Dr Daniel Poulter's Parliamentary office), and the staff of the Parliamentary Health and Wellbeing Service for their support in this study.

Contributors DP and GT conceived the original idea for the study, which was then discussed with NV and with RR coordinated the study. All authors contributed to the design of the study. RR and JD-M conducted the literature review. DP and NV collected the data. IB conducted the design and analysis of the data. JD-M supported the design of the data analysis and contributed throughout the design and writing up of the study. RR and IB led the writing of the manuscript, and all authors contributed and critically revised it. All authors have given their approval for the publication of this manuscript and agree to be accountable for all aspects of the work to ensure that the questions related to the accuracy or integrity of any part of the work are appropriately investigated and resolved.

Funding The authors have not declared a specific grant for this research from any funding agency in the public, commercial or not-for-profit sectors.

Competing interests NV acknowledges funding from the Economic and Social Research Council (ESRC) and National Institute for Health Research (NIHR) Collaboration for Leadership in Applied Health Research and Care South London at King's College London NHS Foundation Trust. GT, IB are supported by the National Institute for Health Research (NIHR) Collaboration for Leadership in Applied Health Research and Care South London at King's College London NHS Foundation Trust. The views expressed are those of the author(s) and not necessarily those of the NHS, the NIHR or the Department of Health. GT acknowledges financial support from the Department of Health via the National Institute for Health Research (NIHR) Biomedical Research Centre and Dementia Unit awarded to South London and Maudsley NHS Foundation Trust in partnership with King's College London and King's College Hospital NHS Foundation Trust. GT is supported by the European Union Seventh Framework Programme (FP7/2007-2013) Emerald project. GT also receives support from the National Institute of Mental Health of the National Institutes of Health under award number R01MH100470 (Cobalt study). GT is also supported by the UK Medical Research Council in relation to the Emilia (MR/ S001255/1) and Indigo Partnership (MR/R023697/1) awards. IB is supported by the NIHR Biomedical Research Centre at South London and Maudsley NHS Foundation Trust and by the NIHR Collaboration for Leadership in Applied Health Research. JD-M has a Clinician Scientist Fellowship, funded by the Health Foundation working with the Academy of Medical Sciences. DP is currently MP of the 57th UK Parliament and was member of the 56th UK Parliament; no other relationships or activities that could appear to have influenced the submitted work.

Patient consent for publication Not required.

Ethics approval Ethics approval for the study was obtained in September 2016 from King's College London Ethics Committee (reference number: HR-16/17-3118).

Provenance and peer review Not commissioned; externally peer reviewed.

Data availability statement All data relevant to the study are included in the article. No additional data available. The APMS 2014 can be accessed at: https:// eur03.safelinks.protection.outlook.com/?url=https $\% 3 \mathrm{~A} \% 2 \mathrm{~F} \% 2 \mathrm{Fdigital.nhs.uk \%}$ 2Fdata-and-information\%2Fpublications\%2Fstatistical\%2Fadult-psychiatricmorbidity-survey $\% 2$ Fadult-psychiatric-morbidity-survey-survey-of-mentalhealth-and-wellbeing-england-2014\&data=01\%7C01\%7Ctony.rao\%40kcl.ac.uk\% 7C168c4b5672524699e2f808d767993f44\%7C8370cf1416f34c16b83c724071 $654356 \% 7 C 0 \&$ sdata $=4$ u9\%2FGOnocJRRxF6dQJvvjs9N2qMq8QdhUI2i29wDfUw\% $3 D \&$ reserved $=0$. Due to the sensibility of the data, and in order to ensure full anonymity, confidentiality and data protection for the participants, the full survey data cannot be made accessible to the public.

Open access This is an open access article distributed in accordance with the Creative Commons Attribution Non Commercial (CC BY-NC 4.0) license, which permits others to distribute, remix, adapt, build upon this work non-commercially, and license their derivative works on different terms, provided the original work is properly cited, appropriate credit is given, any changes made indicated, and the use is non-commercial. See: http://creativecommons.org/licenses/by-nc/4.0/.

\section{ORCID iDs}

Rahul Rao http://orcid.org/0000-0002-0262-5122

Nicole Votruba http://orcid.org/0000-0003-0680-1290

\section{REFERENCES}

1 HM Government. The Government's Alcohol Strategy. London: The Stationary Office Limited, 2012. Available: https://assets.publishing. service.gov.uk/government/uploads/system/uploads/attachment data/file/224075/alcohol-strategy.pdf

2 Office of National Statistics. Alcohol-specific deaths in the UK: registered in 2017. Office of National Statistics, 2018a. Available: https://www.ons.gov.uk/peoplepopulationandcommunity/ healthandsocialcare/causesofdeath/datasets/alcoholspecificdeath sintheukmaindataset

3 Public Health England. Local alcohol profiles for England: Feb 2019 data update. Available: https://fingertips.phe.org.uk/profile/ local-alcohol-profiles/data\#page/11/gid/1938132984/pat/6/par/ E12000004/ati/102/are/E06000015

4 Roberts E, Morse R, Epstein S, et al. The prevalence of wholly attributable alcohol conditions in the United Kingdom hospital system: a systematic review, meta-analysis and meta-regression. Addiction 2019;114:1726-37.

5 Office of National Statistics. Adult drinking habits. Office of National Statistics, 2018b. Available: https://www.ons.gov.uk/peoplepopula tionandcommunity/healthandsocialcare/drugusealcoholandsmoking/ bulletins/opinionsandlifestylesurveyadultdrinkinghabitsingreatbritain/ 2017

6 O'Neill D, Britton A, Brunner EJ, et al. Twenty-five-year alcohol consumption trajectories and their association with arterial aging: a prospective cohort study. J Am Heart Assoc 2017;6:e005288.

7 Topiwala A, Allan CL, Valkanova V, et al. Moderate alcohol consumption as risk factor for adverse brain outcomes and cognitive decline: longitudinal cohort study. BMJ 2017;357:j2353.

8 Roche AM, Lee NK, Battams S, et al. Alcohol use among workers in male-dominated industries: a systematic review of risk factors. Saf Sci 2015;78:124-41.

9 House of Commons. Staff Handbook. Department of Human Resources and Change, 2012. Available: https://www.parliament.uk/ documents/commons-resources/staff-handbook-june2012.pdf 
10 Poulter D, Votruba N, Bakolis I, et al. Mental health of UK members of parliament in the house of commons: a cross-sectional survey. BMJ Open 2019;9:e027892.

11 Equator Network. The strengthening the reporting of observational studies in epidemiology (STROBE) statement: guidelines for reporting observational studies. Available: http://www.equator-network.org/ reporting-guidelines/strobe/

12 Office of National Statistics. Adult psychiatric morbidity survey: survey of mental health and wellbeing, England, 2014. Available: https://digital.nhs.uk/data-and-information/publications/statistical/ adult-psychiatric-morbidity-surveyadult-psychiatric-morbiditysurvey-survey-of-mental-health-and-wellbeing-england-2014\# summary

13 Saunders JB, Aasland OG, Babor TF, et al. Development of the alcohol use disorders identification test (AUDIT): WHO collaborative project on early detection of persons with harmful alcohol consumption, part II. Addiction 1993;88:791-804.

14 Room R, Babor T, Rehm J. Alcohol and public health. Lancet 2005;365:519-30.

15 Goldberg DP, Gater R, Sartorius N, et al. The validity of two versions of the GHQ in the WHO study of mental illness in general health care. Psychol Med 1997;27:191-7.

16 Goldberg DP, Blackwell B. Psychiatric illness in general practice: a detailed study using a new method of case identification. BMJ 1970;2:439-43.

17 Goldberg DP, Hillier VF. A scaled version of the general health questionnaire. Psychol Med 1979;9:139-45.

18 Craig R, Fuller E, Mindell J, (eds). Health Survey for England 2014, London: the Health and Social Care Information Centre, 2015. Available: https://digital.nhs.uk/data-and-information/publications/ statistical/health-survey-for-england/health-survey-for-england2014

19 StataCorp. Stata Statistical Software:Release 14. College Station, TX: StataCorp LP, 2015.

20 Höffler M, Pfister H, Lieb R, et al. The use of weights to account for non-response and drop-out. Soc Psychiatry Psychiatr Epidemiol 2005;40:291-9.

21 All-Party Parliamentary Group on Mental Health. Mental health in Parliament: report by the all- party parliamentary group on mental health, 2008. Available: http://www.lynnejones.org.uk/lynne-jones$\mathrm{mp} /$ survey\%20FINAL.pdf

22 Hendriks VM, Garretsen HFL, van de Goor LAM. A "parliamentary inquiry" into alcohol and drugs: a survey of psychoactive substance use and gambling among members of the Dutch parliament. Subst Use Misuse 1997;32:679-97.
23 van de Borne P, Persu A, Andries A, et al. Elevated prevalence of arterial hypertension in the Belgian parliament. $J$ Hypertens 2005;23:2109.

24 Kohvakka A, Palmroos P, Koivu TA, et al. Trends in serum cholestero and lifestyle indicators in members of the Finnish Parliament. Public Health 2003;117:11-14.

25 Gyntelberg F, Suadicani P, Jensen G, et al. Job strain and cardiovascular risk factors among members of the Danish Parliament. Occup Med 1998;48:31-6.

26 Politico. Belgian MPs to keep free alcohol in Parliament. Available: https://www.politico.eu/article/belgian-mps-to-keep-free-alcohol-inparliament/ [Accessed 29 Nov 2019].

27 James DV, Farnham FR, Sukhwal S, et al. Aggressive/intrusive behaviours, harassment and stalking of members of the United Kingdom Parliament: a prevalence study and cross-national comparison. J Forens Psychiatry Psychol 2016;27:177-97.

28 Kuehner C, Gass P, Dressing H. Increased risk of mental disorders among lifetime victims of stalking--findings from a community study. Eur Psychiatry 2007;22:142-5.

29 Weinberg A, Cooper CL, Weinberg A. Workload, stress and family life in British members of parliament and the psychological impact of reforms to their working hours. Stress Med 1999;15:79-87.

30 Weinberg A, Cooper CL. Stress among national politicians elected to Parliament for the first time. Stress Health 2003;19:111-7.

31 Wilhelm K, Kovess V, Rios-Seidel C, et al. Work and mental health. Soc Psychiatry Psychiatr Epidemiol 2004;39:866-73.

32 Thornicroft G, Mehta N, Clement S, et al. Evidence for effective interventions to reduce mental-health-related stigma and discrimination. Lancet 2016;387:1123-32.

33 Wykes T, Craig T. Can our politicians help to reduce stigma and discrimination? J Ment Health 2013.

34 Royal College of Psychiatrists. Our invisible addicts: Second Report of the Older Persons' Substance Misuse Working group of the Royal College of Psychiatrists. Royal College of Psychiatrists, 2018. Available: https://www.rcpsych.ac.uk/docs/default-source/ improving-care/better-mh-policy/college-reports/college-reportcr211.pdf?sfvrsn=820fe4bc 2

35 Rao R, Schofield P, Ashworth M. Alcohol use, socioeconomic deprivation and ethnicity in older people. BMJ Open 2015; 5:e007525

36 UK Parliament. New support announced for MPs with mental health problems, 2013. Available: http://www.parliament.uk/business/ committees/committees-a-z/other-committees/members-estimate/ news/new-support-announced-for-mps-with-mental-healthproblems/ 
Correction: Alcohol consumption of UK members of parliament: cross-sectional survey

Rao R, Bakolis I, Das-Munshi J, et al. Alcohol consumption of UK members of parliament: cross-sectional survey. BMJ Open 2020;10:e034929. doi: 10.1136/bmjopen-2019-034929

This article was previously published with an error.

Affiliations of authors should be:

Rahul Rao ${ }^{1}$, Ioannis Bakolis ${ }^{2}$, Jayati Das-Munshi ${ }^{3}$, Daniel Poulter ${ }^{4}$, Nicole Votruba ${ }^{5}$, and Graham Thornicroft ${ }^{5}$

${ }^{1}$ Old Age Psychiatry, Institute of Psychiatry, Psychology and Neuroscience, London, UK ${ }^{2}$ Department of Biostatistics and Health Informatics/Centre for Implementation Science, Institute of Psychiatry, Psychology and Neuroscience, King's College London, London, UK

${ }^{3}$ Department of Psychological Medicine, Institute of Psychiatry, Psychology \& Neurosciences, King's College London, Institute of Psychiatry, London, UK

${ }^{4}$ House of Commons, London, UK

${ }^{5}$ Centre for Global Mental Health, Institute of Psychiatry, Psychology and Neuroscience, King's College London, London, UK

The information 'Rahul Rao and Ioannis Bakolis are joint first authors.' was missing.

The line in competing interest 'GT, IB are supported by the National Institute for Health Research (NIHR) Collaboration for Leadership in Applied Health Research and Care South London at King's College London NHS Foundation Trust.' should read 'GT is supported by the National Institute for Health Research (NIHR) Collaboration for Leadership in Applied Health Research and Care South London at King's College London NHS Foundation Trust.'

Open access This is an open access article distributed in accordance with the Creative Commons Attribution Non Commercial (CC BY-NC 4.0) license, which permits others to distribute, remix, adapt, build upon this work non-commercially, and license their derivative works on different terms, provided the original work is properly cited, appropriate credit is given, any changes made indicated, and the use is non-commercial. See: http://creativecommons.org/licenses/by-nc/4.0/.

(C) Author(s) (or their employer(s)) 2020. Re-use permitted under CC BY-NC. No commercial re-use. See rights and permissions. Published by BMJ.

BMJ Open 2020;10:e034929corr1. doi:10.1136/bmjopen-2019-034929corr1

Q Check for updates 